\title{
Sapphire subdivision at different heat treating types
}

\author{
R.Ye.Brodskii, P.V.Konevskiy, R.I.Safronov, A.V.Voloshin \\ SSI "Institute for Single Crystals", STC"Institute for Single Crystals" \\ National Academy of Sciences of Ukraine, \\ 60 Nauky Ave., 61001 Kharkiv, Ukraine
}

\section{Received February 20, 2017}

\begin{abstract}
In the work the results of experimental investigation of fragmentation of sapphire samples subjected to various types of heat treating are given. It was studied the fragmentation of the samples subjected to short and long annealing in vacuum, and the samples annealed in a hydrogen atmosphere. For each type of heat treating it was received the distribution of sapphire fragments by masses, asymptotics of the distribution at the large-scale region and found the crack resistance coefficient. The results are were compared with the results of investigation of fragmentation of the sapphire samples not subjected to heat treating.
\end{abstract}

Keywords: fragmentation samples, sapphire, resistance coefficient.

Приведены результаты экспериментального исследования фрагментации образцов лейкосапфира, подвергнутых различного типа термообработке. Изучена фрагментация образцов, подвергнутых краткому и длительному отжигу в вакууме, а также отожжённых в атмосфере водорода. Для каждого типа термообработки получено распределение осколков образцов сапфира по массе, асимптотика этого распределения в крупномасштабной области и найден коэффициент трещиностойкости. Проведено сравнение полученных результатов с результатами исследования фрагментации образцов сапфира, не подвергавшшхся термообработке.

Подрібнення сапфіру при термообробці різного типу. Р.E. Бродський, П.В. Коневський, Р. Софронов, О. Волошин.

Наведено результати експериментального дослідження фрагментації зразків лейкосапфира, підданих різного типу термообробці. Вивчено фрагментацію зразків, підданих короткому і тривалому відпалу у вакуумі, а також відпалених в атмосфері водню. Для кожного типу термообробки отримано розподіл уламків зразків сапфіра за масою, асимптотика цього розподілу у великомасштабній області і знайдено коефіцієнт тріщиностійкості. Проведено порівняння отриманих результатів з результатами дослідження фрагментації зразків сапфіра, що не піддавалися термообробці.

\section{Introduction}

We have studied impact fragmentation of leucosapphire, which subjected to the heat treating of various types.

Leucosapphire, or sapphire is transparent crystal of high hardness and strength. It is used as a structural material for making of the elements of a transparent protection. Therefore, study of its strength properties and impact fracture process is important.
The fragmentation of brittle material is the random process, as a result of which many "fragments" of different sizes are formed. In fragmentation theory the studied processes can be classified according to several criteria. One of them is the dimension of the fragments, in this case one-, two- and three-dimensional fragmentation are distinguished. The other is a way to impact, in this case one distinguish singleimpact, or as it is called in [1], "weak" 
fragmentation and multi-impact or "strong" fragmentation.

The paper presents results of an experimental investigation of three-dimensional "weak" fragmentation. Distributions of the fragments by mass is obtained. It is made comparison of these distributions with distributions, obtained analytically in the fragmentation theory.

Under shock destruction the impact energy mainly spent on formation of a new surface. Ratio of the energy expended in the destruction of material to the new surface area can be characteristic of strength of the material. However, to determine the energy expended on the destruction, it is necessary to know not only the impact energy, but also the energy that was dispersed and did not go to the material destruction.

It can use another, more convenient, criterion for comparing the strength of different materials, which does not require knowledge of the energy expended to break. To do this, it makes experiments with samples of compared materials with the same impact energy and the same shape and size of the sample. Then, for each sample it calculates the ratio of area of the new formed upon impact surface to area of surface of the original sample. This ratio is called crack resistance coefficient. On the basis of obtained values of the crack resistance coefficient the conclusion is made about which material is stronger.

In [2] the results of research of leucosapphire fragmentation are not subjected to heat treating presented. It was obtained distributions of fragments by mass and calculated the crack resistance coefficient. Asymptotics of the distribution density in a large-scale area is found. The resulting asymptotic behavior corresponds to the asymptotic behavior theoretically ground in [1]. The same asymptotics observed in experiments on the destruction of other materials [3-6], which speaks about its versatility.

The heat treating (annealing) of the sample affects its strength properties. In the paper we investigated the fragmentation of sapphire samples annealed in vacuum and in a hydrogen atmosphere. It made comparison with the fragmentation of the sapphire samples which are not subjected to the heat treatment [2]. For each type of annealing the distribution density of the fragments by masses was obtained, the asymptotics of this density in the large-scale area is found

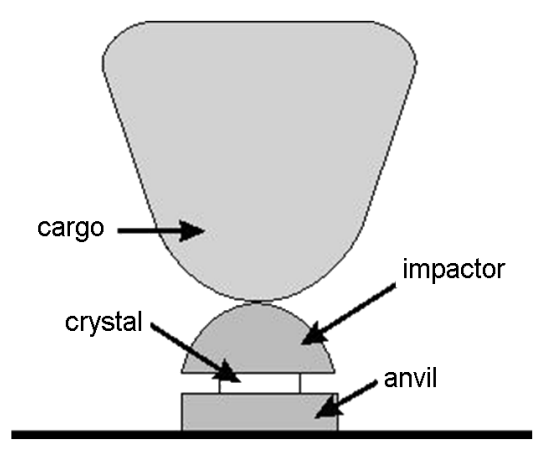

Fig. 1. Scheme of device for samples destruction.

and the crack resistance coefficient is calculated.

\section{Experimental}

In the experiment, samples of leucosapphire, that were subjected to impact, had form of disk with diameter of $4.4 \mathrm{~mm}$ and $1.2 \mathrm{~mm}$ in height. The samples were cut from crystal of sapphire previously annealed in vacuum, the samples were grinded after cutting, part of the samples was then annealed in a hydrogen atmosphere, part was subjected to a the short $(2 \mathrm{~h})$ and part to a the long $(6 \mathrm{~h})$ vacuum annealing at a temperature of 1850 degrees.

The samples were placed under a metal impactor, evenly distributed force on the sample surface. It was made impact to drummer by cargo falling from a predetermined height. Device is shown in Fig. 1. In the experiments the drop height was taken $18 \mathrm{~cm}$, such impact makes possible to obtain from the samples with the given above parameters the pieces in a wide range of sizes: large and comparable in size to with the original sample, as well as fine "dust". At lower loads the samples with given parameters in many experiments were not destroyed, at greater destroyed into a fine powder, which makes further measurements difficult. In [2] the same parameters of the samples and the same parameters of device for their destruction were used, that allowed the results comparison.

Masses of the fragments were determined as follows. The fragments from each experiment were collected on a flat glass substructure and photographed (Fig. 2), and then the areas $S_{i m g}$ of their images on the photo were determined in pixels. Next, with these areas, fragment masses were calculated. For the conversion of the areas in pixels to the areas in $\mathrm{mm}^{2}$ the scale strips were made on the substructure. It was determined that $1 \mathrm{~mm}$ on the substructure corresponds to 
48 pixels on the pictures, i.e. $1 \mathrm{~mm}^{2}$ corresponds to the image area in the picture of $48^{2}$ or 2304 pixels.

Since the area of the fragment projection grows at a constant form as square of the fragment size, and mass - as a cube, the fragment mass $m$ can be calculated from the projection area in $\mathrm{mm}^{2} S$ as

$$
m=\rho \cdot \alpha S^{3 / 2},
$$

where $\rho$ - material density, for sapphire $4 \mathrm{~g} / \mathrm{cm}^{3}, \quad \alpha-$ coefficient, depending on fragment form, formfactor.

In [2] coefficient $\alpha$ was determined experimentally. Large fragments were weighed on the scales, and then weighing results were compared with the results of photographing. The calculated coefficient was equal to $\alpha \approx 0.63$. This factor was used to determine the masses of the remaining, smaller fragments, for which direct weighing difficult. Pointed coefficient was used in this work.

Error in the calculation of the mass and crack resistance coefficient determined from the error in calculation of the area $S$ of the projection of the fragment on substructure. This area was calculated from the area of the fragment image in the photo. The image area (number of pixels in image) $S_{i m g}$ is determined with error equal to half of perimeter (the number of pixels on the image bound) $P_{i m g}$ of the image. Observation under a microscope showed that the fragments form similar to plates with thickness less than the other two, approximately equal, sizes. For such samples $P_{i m g} / 2 \approx 2 \sqrt{S_{i m g}}$. Three sets of mass was obtained $-m_{i}, m_{i}^{\text {down }}, m_{i}^{u p}$, for image areas, equal to $S_{i m g}, S_{i m g}-2 \sqrt{S_{i m g}}$ and $S_{i m g}+$ $2 \sqrt{S_{i m g}}$, accordingly. Mass distribution densities $p, p^{d o w n}, p^{u p}$ were obtained from these three sets.

For each type of heat treating the crack resistance coefficient $C$ was calculated, it equal to

$$
C=\frac{S_{f}-S_{0}}{S_{0}},
$$

where $S_{f}$ - the total surface area of fragments, $S_{0}-$ initial sample surface area, thus, $S_{f}-S_{0}-$ area of the new, formed by impact, surface. Exactly on formation of this surface the energy is consumed in shock destruction.

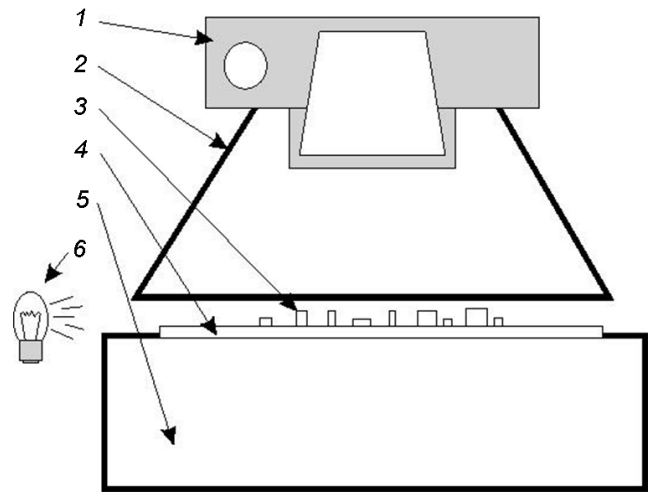

Fig. 2. Scheme of sample fragments photographing: 1 - camera, 2 - screen that protects camera lens from the side illumination, 3 - fragments of sample after crushing, 4 quartz slide, 5 - a black box, which provides a dark background for sample fragments, 6 - backlight for sample fragments.

The area $S_{f}$ is sum of the surface areas of the individual fragments. The surface area $S_{\text {surf }}$ of each fragment is proportional to area $S$ of its projection on the substructure,

$$
S_{\text {surf }}=\beta S,
$$

factor $\beta$ is determined by shape of the sample. For samples in the form of plate with approximately same sizes in the plane of projection with the found above factor $\alpha$, factor $\beta \approx 4.52$. As for the masses, three values of the crack resistance coefficient $C$, $C^{\text {down }}, C^{\text {up }}$ were calculated from the areas of projections $S_{i m g}, S_{i m g}-2 \sqrt{S_{i m g}}$ and $S_{i m g}+$ $2 \sqrt{S_{i m g}}$. The values $C^{\text {down }}, C^{u p}$ used to calculate the error.

\section{Results and discussion}

Let's remind the results of the experiments on fragmentation of not annealed sapphire samples [2]. The samples in the form of $4.4 \mathrm{~mm}$ diameter discs with $1.2 \mathrm{~mm}$ height were cut from a one rod, as described in the section above, and polished. The samples were not subjected to further annealing after polishing. In this case, the average number of fragments per original sample was equal to $n=121.74$.

The distribution density of the fragments number by mass in this case is shown in Fig. 3, left side. Graph is given in a double logarithmic scale. Symbols "口", "+" and " $\times$ " marks the densities values $p, p^{\text {down }}$, $p^{u p}$, respectively. Fig. 3 on the right shows 

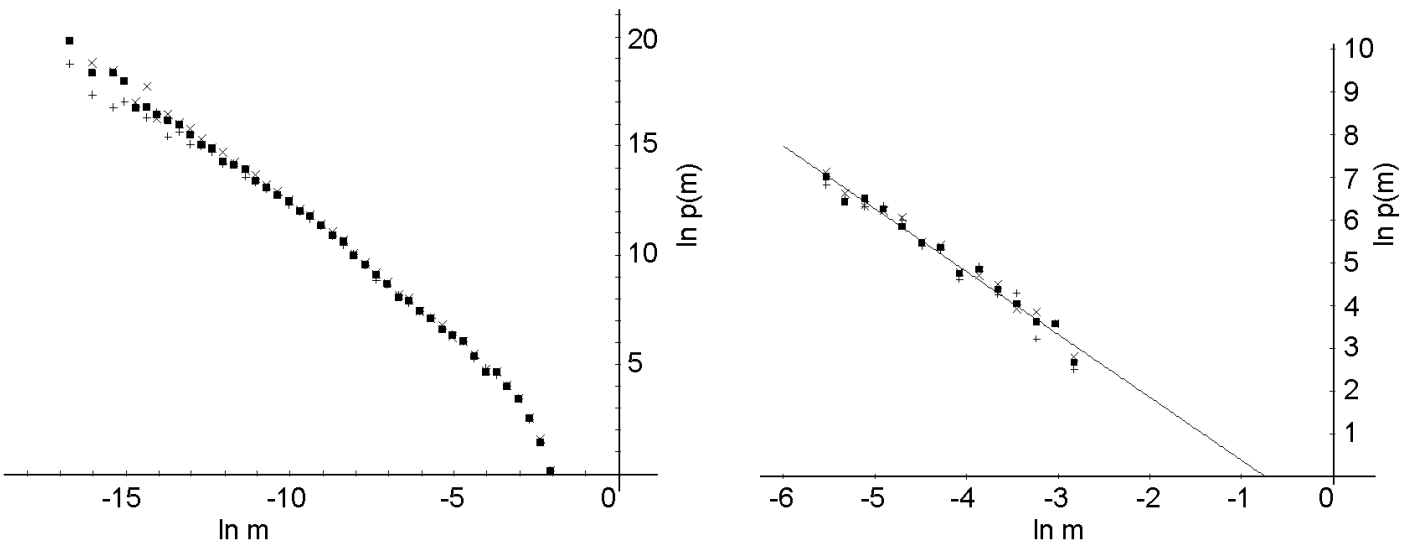

Fig. 3. On the left - distribution density of fragments by mass for sapphire without heat treating (in double logarithmic scale), on the right - a large-scale region of density and asymptotics in this area.

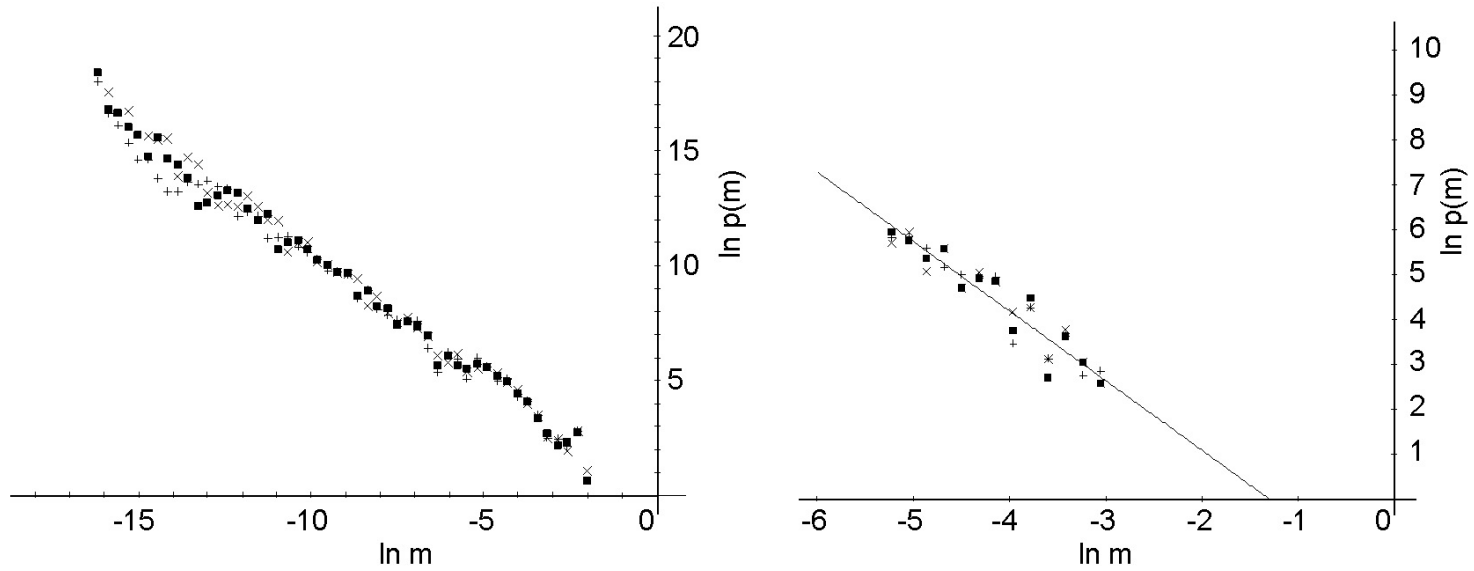

Fig. 4. On the left - distribution density of fragments by mass for sapphire samples annealed in hydrogen atmosphere (in double logarithmic scale), on the right - a large-scale region of density and asymptotics in this region.

a large-scale region of the density and found asymptotics, power, linear in a log$\log$ scale. The asymptotics was found as a linear approximation of the large-scale part of the obtained density using the least squares method. (The rightmost points on the graph correspond to the not destroyed samples, and need not be taken into account in the construction of the asymptotics).

Large-scale asymptotics of the density have the form

$$
p_{m} \sim m^{\gamma}, \quad \gamma=-1.52 \pm 0.01 \text {. }
$$

To determine the error of exponent $\gamma$ asymptoticses of the densities $p^{\text {down}}, p^{u p}$ was build, and as the error a larger deviation of exponents of these asymptoticses from the exponent of asymptotics $p$ was taken.

The distribution density asymptotics of mass with the form $p_{m} \sim m^{-1.52}$ corresponds to the asymptotics of the distribution density of fragment sizes with the form

$$
p_{r}=r^{-2.56} \text {. }
$$

The power asymptotics $p_{r} \sim r^{-2.5}$ was theoretically ground in [1].

The crack resistance coefficient for the case of not annealed samples is equal to

$$
C \approx 2.69 \pm 0.15 \text {. }
$$

Here the crack resistance coefficient obtained with the correction of typos in [2]. (In [2] the total surface area of the fragments of all the experiments is taken as the total surface area of the fragment in the formula for crack resistance coefficient, not of one experiment).

The greater of deviations of the coefficients $C^{\text {down }}, C^{\text {up }}$ from $C$ is taken as an error.

Let us turn to the results of experiments on fragmentation of sapphire samples subjected to the heat treating. For the case of fragmentation of the samples annealed in 


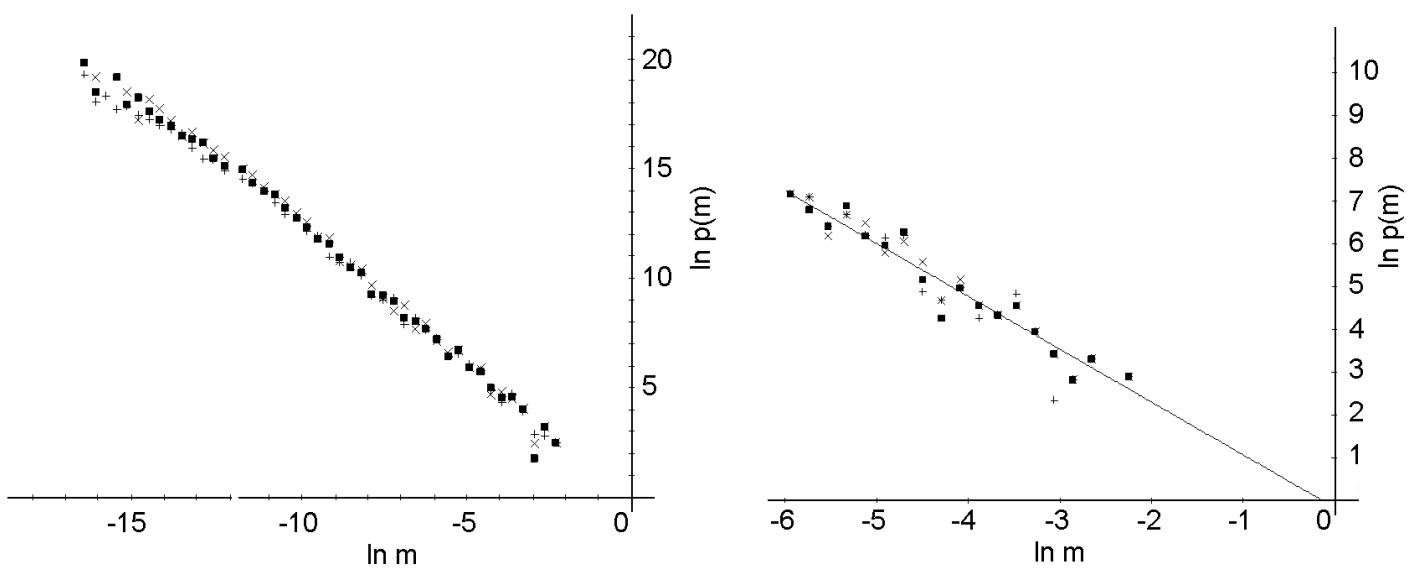

Fig. 5. On the left - distribution density of fragments by mass for sapphire samples subjected to short annealing in vacuum (graph given in double-logarithmic scale), on the right - large-scale region of density and asymptotics in this region.5. On the left - distribution density of fragments by mass for sapphire samples subjected to short annealing in vacuum (graph given in double-logarithmic scale), the right - large-scale region of density and asymptotics in this region.

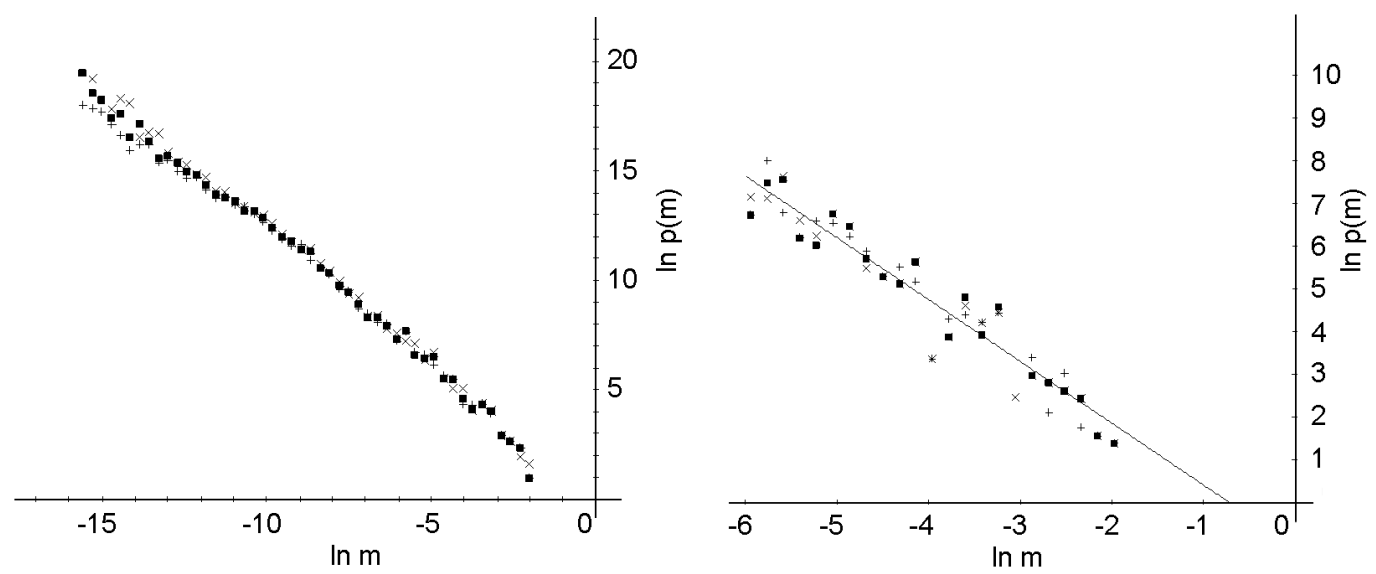

Fig. 6. On the left - distribution density of fragments by mass for sapphire samples subjected to long annealing in vacuum (graph given in double logarithmic scale), on the right — a large-scale region of distribution density and the asymptotics in this region.

hydrogen atmosphere, the graph of fragments distribution density by masses shown in Fig. 4, left. Right - there is a largescale region of the density and the asymptotics.

The asymptotics in large-scale region has the form

$$
p_{m} \sim m^{\gamma}, \quad \gamma=-1.55 \pm 0.1,
$$

i.e. close to obtained above for the not annealed samples. The number of fragments per experiment in this case was $n=24$ that 5 times less than for not annealed samples. Crack resistance coefficient

$$
C \approx 1.206 \pm 0.054
$$

is approximately two times lower than for the not annealed samples. Reducing of the number of fragments and a reducing of the crack resistance coefficient show that sapphire samples annealed in a hydrogen atmosphere obtain an appreciable greater strength compared to the not annealed samples. Significantly reducing of the total number of fragments per experiment indicates that mainly large fragments was split off, i.e. tendency to chipping fine "dust" during annealing in hydrogen decreases particularly strongly.

Let us now consider fragmentation of the sapphire samples annealed in vacuum. Two series of experiments were carried out with a short and a long annealing at the 

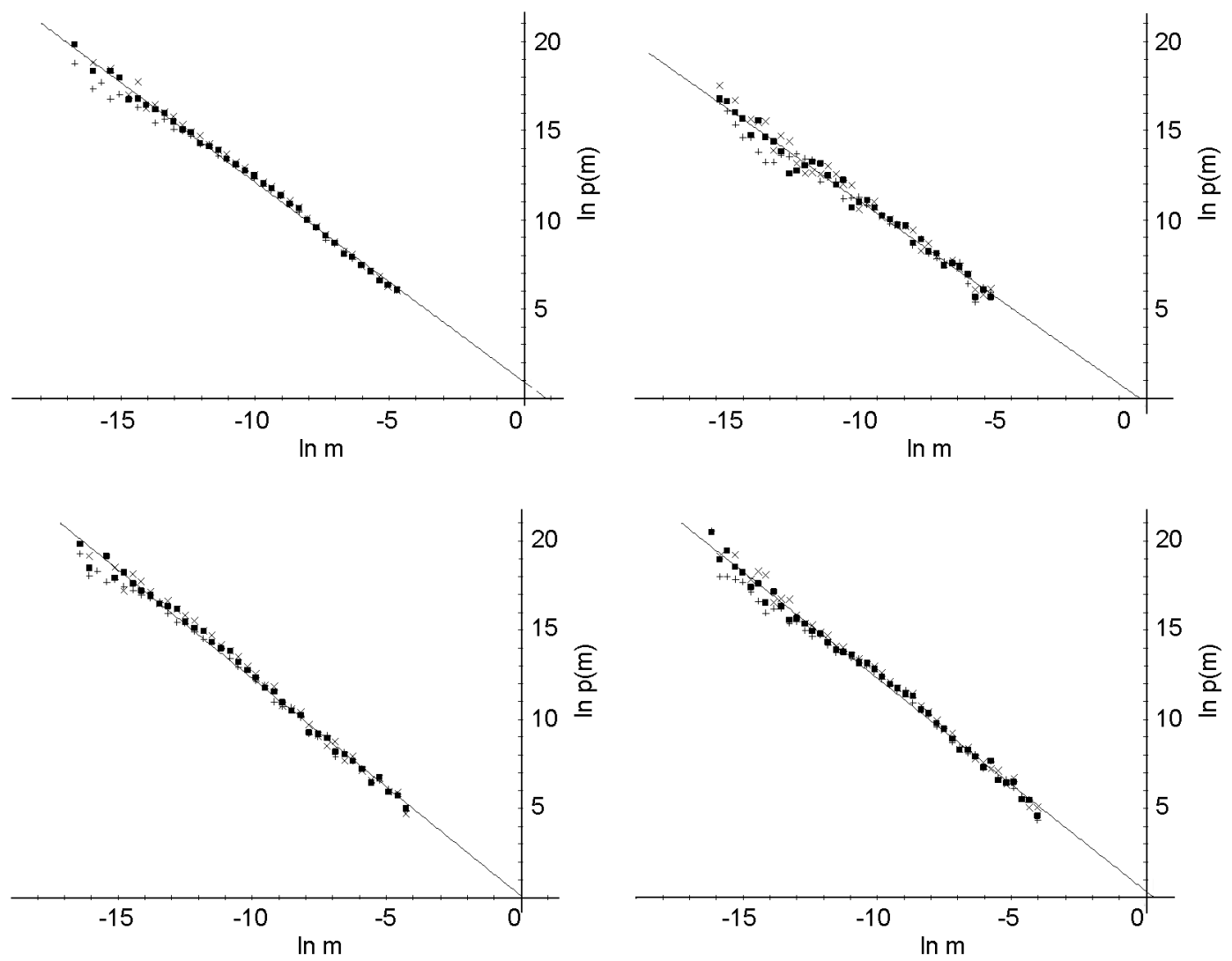

Fig. 7. Small-scale part of distribution density of fragments by masses and linear approximations in this region for the samples (from left to right and top to bottom) of sapphire without heat treating, the samples annealed in hydrogen, samples a short annealing in vacuum and long annealing in vacuum.

temperature of 1850 degrees. The distribution density in the case of short annealing, it's large-scale region and the asymptotics in this region are shown in Fig. 5.

In this case, a large-scale asymptotics close to

$$
p_{m} \sim m^{\gamma}, \quad \gamma=-1.235 \pm 0.063 .
$$

The number of fragments per the experiment in this case $n \approx 181$, it is greater than in the case of the not annealed samples. Crack resistance coefficient is

$$
C \approx 3 \pm 0.17,
$$

i.e. larger than for the not annealed sapphire samples. Comparing both values with the case of not subjected to the heat treating sapphire shows that the sapphire strength decreases at annealing in vacuum.

Finally, distribution density of the fragments by mass in the case of long annealing in vacuum, large-scale region of the density and the asymptotics in the large-scale region shown in Fig. 6. In this case the asymptotics is close to

$$
p_{m} \sim m^{\gamma}, \quad \gamma=-1.447 \pm 0.056
$$

The number of fragments per experiment in the case of long annealing in vacuum is $n \approx 172.7$, which is more than in the case of the not annealed sapphire samples and practically the same (a little less) than in the case of a the short annealing.

The crack resistance coefficient is

$$
C \approx 3.28 \pm 0.17 \text {, }
$$

more than for the not annealed samples and more than for the sapphire samples subjected to the short annealing. Thus, this experiment shows that the annealing in vacuum reduces the strength of sapphire in shock destruction. With increasing of annealing time the crack resistance coefficient increases.

Note, that in the small-scale part of the data the density distribution in each case is also close to linear in the double logarithmic scale, i.e., to the power (Fig. 7). We call "small-scale" the part of region of the den- 
sity remote from the large-scale part, analyzed above. The exponent value of this approximation is $\gamma \approx-1 . .-1.2$, that higher (lower in the absolute value) than in the large-scale area.

Proximity of this part to the power can be explained, apparently, by the following. A found from the general principles in the fragmentation theory distribution density ([1], formula (20), Fig. 1), has the form of a curve with a single maximum and a slow decrease. Obtained in the present paper the small-scale region corresponds to this region of decreasing. Indeed, it can be seen small deviations from a straight line - the density crosses the line from the top to down (visible on the graphs for the not annealed samples of sapphire and the sapphire samples annealed in vacuum).

Thus, the proximity of the received density to the power means only that get (or measure) the fragments from the expected maximum region and smaller in conditions of the present experiment is impossible. The linear approximation is an "average" derivative of the density in this region.

Fact, that approximation exponent increases with decreasing of size of the fragments confirmed the assumption about presence of the maximum (exponent $\gamma=0$ ) in small sizes.

\section{Conclusions}

In the work the results and analysis of the experimental investigation of heat treated leucosapphire fragmentation are given. The following results were obtained.

It is shown that asymptotics of fragments masses distribution density in a large-scale region have the form $p_{m} \sim m^{\gamma}$, where $\gamma$, depending on the heat treating form is equal to $\gamma \approx-1.23 \ldots 1.55$ (Fig. 4,5 and 6 , right). The power asymptotics with exponent $\gamma=-1.5$ in the region of large scales was theoretically ground in [1]. For the case of sapphire not subjected to the heat treating the power asymptotics was also obtained with $\gamma \approx-1.52$ [2] (Fig. 3 right).
When the samples are annealed in hydrogen atmosphere, the number of fragments per original sample is $n=24$, that is about 5 times lower than without the heat treating $(n=121.74)$. In this case the crack resistance coefficient is equal to $C \approx 1.206 \pm 0.054$, that is less than in the case of the not annealed samples $(C \approx 2.69 \pm 0.15)$ approximately twice. This means that annealing in a hydrogen atmosphere increases the sapphire strength and particularly reduces the tendency to chipping of the small fragments.

In the case of annealing in vacuum, the number of pieces per the experiment is $n \approx 181$ for short annealing $(2 \mathrm{~h})$ and $n \approx 172.7$ for a long $(6 \mathrm{~h})$, that is more than in the case of the not annealing samples. The crack resistance coefficients are equal to correspondingly $C \approx 3 \pm 0.17$ for the short and $C \approx 3.28 \pm 0.17$ for the long annealing in vacuum. Both values are higher than in the case without heat treating. This means that the vacuum annealing reduces material shock fracture strength.

In the small-scale region distribution the density of fragments onmasses is also close to linear in the log-log scale. This means that the data obtained in the experiment are far enough from the peak region. Density graphs in the small-scale region and corresponding linear approximations are shown in Fig. 7.

Acknowledgements. The authors thank Prof. V.V.Yanovsky for the many valuable recommendations received during the work and when writing the article.

\section{References}

1. V.V.Yanovsky, A.V.Tur, O.V.Kuklina, $Z h$. $E k$ sper. i Teor. Fiz., 137, 986 (2010).

2. R.Ye.Brodskii, P.V.Konevskiy, R.I.Safronov, Functional Materials, 18, 200 (2011).

3. W.K.Hartmann, Icarus, 10, 201 (1969).

4. T.Ishii, M.Matsushita, J.Phys.Soc.Jpn., 61, 3474 (1992).

5. L.Oddershede, P.Dimon, J.Bohr, Phys. Rev. Lett., 71, 2107 (1993).

6. A.Meibom, I.Balslev, Phys. Rev. Lett., 76, 2492 (1996). 